\title{
Moisture-dependent orthotropic viscoelastic properties of Chinese fir wood in low temperature environment
}

\author{
Zhu $\mathrm{Li}^{1}$ · Jiali Jiang ${ }^{1}$. Jianxiong $\mathrm{Lu}^{1}$
}

Received: 23 March 2018 / Accepted: 21 May 2018 / Published online: 20 June 2018

(C) The Japan Wood Research Society 2018

\begin{abstract}
The influence of moisture content (MC) on the orthotropic viscoelasticity of Chinese fir wood (Cunninghamia lanceolata [Lamb.] Hook.) has been examined in low temperature environment. Storage modulus $E^{\prime}$ and loss modulus $E^{\prime \prime}$ of wood with six different levels of $\mathrm{MC}$ ranging from 0.6 to $22.0 \%$ were determined from -120 to $40{ }^{\circ} \mathrm{C}$ and at multi-frequency range of $0.5,1,2,5$, and $10 \mathrm{~Hz}$ using a TA instruments ${ }^{\circledR}$ Dynamic Mechanical Analyzer (DMA 2980). The results showed that a distinct moisture dependency is exhibited by the orthotropic viscoelastic behaviour of Chinese fir wood. With the exception of some apparent activation energy $(\Delta E)$ for $\beta$-relaxation process, the $E^{\prime}$ decreased and the $E^{\prime \prime}$ peak temperatures moved towards lower temperature and the $\Delta E$ for $\alpha$-relaxation process became lower with MC increasing in all orthotropic directions, whereby individual decline of $E^{\prime}$ and the $E^{\prime \prime}$ peak temperatures were affected by $\mathrm{MC}$ to different degrees. Besides, a little $E^{\prime \prime}$ peak at around $0{ }^{\circ} \mathrm{C}$ was only seen in $\mathrm{L}$ direction, which could be attributed to the melting of frozen water. Furthermore, the dynamic viscoelastic behavior of wood is also dependent on the measurement frequency. The findings suggest that the orthotropic structure and moisture content have an important influence on the viscoelastic performance in low temperature environment.
\end{abstract}

Keywords Chinese fir wood $\cdot$ Moisture content $\cdot$ Orthotropic viscoelasticity $\cdot$ Tension $\cdot$ Low temperature

\section{Introduction}

As a highly complex cellular composite, wood by nature is hygroscopic. Therefore, its mechanical property is moisturedependent [1-3], not exception for viscoelastic properties. As wood is exposed to varying climatic conditions in many applications, both temperature and moisture content (MC) play leading roles in influencing the mechanical properties of wood. Therefore, the information on wood viscoelastic property and temperature or MC relationship is of particular interest. Furthermore, given the distinctive anisotropy of wood, a complete viscoelastic characterization further

Jiali Jiang

jialiwood@caf.ac.cn

Zhu Li

lizhu@caf.ac.cn

Jianxiong Lu

jianxiong@caf.ac.cn

1 State Key Laboratory of Tree Genetics and Breeding, Research Institute of Wood Industry, Chinese Academy of Forestry, Beijing, 100091, People's Republic of China requires knowledge of the viscoelasticity related to the three principal axes: longitudinal (L), radial (R) and tangential (T).

Due to the increased use of numerical models in materials science and engineering that consider the time dependence of mechanical behavior, there has been a rising demand for viscoelastic properties of wood. Although several researchers investigated the influence of the temperature on the thermal softening behavior of wood [4-6], a few studies illustrated the wood viscoelasticity in low temperature environment. When the timber used for snowboard or the roof of wooden-structural housing, it is of interest to know how its viscoelastic properties are influenced by negative temperatures. Previous researches showed that the storage modulus or the modulus of elasticity of wood tended to increase when wood was cooled below room temperature [7-10]. However, there was no systematic study evaluating the moisture-dependent anisotropic viscoelastic parameters for wood materials under low temperature conditions.

As MC increases, a decrease in stiffness and an increase in damping can be observed when wood is under dynamic loading conditions. Numerous studies have been carried out 
on the moisture dependence of the viscoelastic properties of wood [4, 5, 11-13]. While the influence of MC on the viscoelastic behavior of wood in longitudinal (L) direction is relatively well known, the behavior in the perpendicular to the grain directions ( $\mathrm{R}$ and $\mathrm{T}$ ) remains scarcely studied. In general, the viscoelasticity only tested for a given grain orientation-MC combination in most investigations were found. Hering and Niemz [14] measured the viscoelastic behavior of European beech wood (Fagus sylvatica L.) in L direction with three different MC levels. Furuta et al. [13] investigated the temperature dependence of the viscoelasticity of Japanese cypress (Chamaecyparis obtusa Endl.) samples saturated with water in $\mathrm{R}$ direction. Consequently, comprehensive datasets comprising the moisture-dependent anisotropic viscoelastic parameters were missing. Viscoelastic parameters based on the three-dimensional approach are, however, essential input-parameters required for advanced computational models used in modern civil engineering.

The presented study aims to contribute towards a better understanding of the moisture-dependent viscoelastic anisotropy of wood in low temperature environment, by providing an extensive set of moisture-dependent viscoelastic parameters for Chinese fir wood, which can be further used for advanced modeling.

In the current research, the parameters comprise storage modulus $E^{\prime}$ and loss modulus $E^{\prime \prime}$ in all orthotropic directions were determined in tension at different $\mathrm{MC}$ under low temperature environment $\left(-120-40{ }^{\circ} \mathrm{C}\right)$. An examination was then conducted to identify factors influencing the responses and the causes of the phenomena were discussed.

\section{Materials and methods}

Specimens were obtained from the heartwood part of Chinese fir wood (Cunninghamia lanceolata [Lamb.] Hook.) without any visual defects and knots. The longitudinal (L), radial $(\mathrm{R})$, and tangential $(\mathrm{T})$ specimens were cut into the dimensions of 35 by 6 by $1.5 \mathrm{~mm}(\mathrm{~L} \times \mathrm{R} \times \mathrm{T}), 35$ by 6 by $1.5 \mathrm{~mm}(\mathrm{R} \times \mathrm{L} \times \mathrm{T})$, and 35 by 6 by $1.5 \mathrm{~mm}(\mathrm{~T} \times \mathrm{L} \times \mathrm{R})$,

Fig. 1 Schematic of specimens in all orthotropic directions. a longitudinal, $\mathbf{b}$ radial, and $\mathbf{c}$ tangential

respectively, as shown in Fig. 1. The air-dried density of specimens was $328 \mathrm{~kg} \mathrm{~m}^{-3}$.

Specimens were divided into six groups and to be conditioned in climatic chambers at $0,20,40,60,80$ and $100 \%$ relative humidity $(\mathrm{RH})$ at a room temperature of $20{ }^{\circ} \mathrm{C}$, respectively. The desired 0 and $100 \% \mathrm{RH}$ was maintained by anhydrous phosphorus pentoxide $\left(\mathrm{P}_{2} \mathrm{O}_{5}\right)$ and distilled water, respectively, and the corresponding $\mathrm{MC}$ was about 0.6 and $22.0 \%$. The other four RH conditions were attained by sulfuric acid solution humidifying method [15]. The sulfuric acid solution with the concentrations of $57.8,48.0,36.5$, and $24.1 \%$ were used to create 20,40 , 60 and $80 \%$ RH conditions, and the corresponding equilibrium moisture content (EMC) was about 3.5, 6.0, 9.3, and $14.1 \%$, respectively.

The viscoelastic properties were measured using a TA instruments ${ }^{\circledR}$ Dynamic Mechanical Analyzer (DMA 2980) apparatus with controlled cooling accessory. The cooling system utilizes liquid nitrogen. The temperature decreased rapidly from room temperature to $-120^{\circ} \mathrm{C}$ at $13^{\circ} \mathrm{C} / \mathrm{min}$ and kept constant at $-120^{\circ} \mathrm{C}$ for $10 \mathrm{~min}$. Then, temperature scans were performed in the range from -120 to $40{ }^{\circ} \mathrm{C}$ with a programmed heating rate of $2{ }^{\circ} \mathrm{C} \mathrm{min}^{-1}$. The viscoelastic parameters were recorded during the rising temperature at each $15 \mathrm{~s}$ interval. Uniaxial tension mode (distance between clamping midpoints, $18 \mathrm{~mm}$ ) was used. The displacement amplitude was $15 \mu \mathrm{m}$ and the force track was $125 \%$. The preload force was $0.01 \mathrm{~N}$. This applied force value was so small that the creep effects could be negligible. The measurement frequencies were $0.5,1,2,5$ and $10 \mathrm{~Hz}$. For each condition, three replicates were tested and one representative curve was shown in the following figures.

There was no climate control in the chamber of the viscoelasticity measuring system, so the moisture loss (or gain) was measured by weighing specimens before and after each test. Moisture loss (or gain) was deemed negligible during the viscoelasticity testing process. The change of moisture content was about $0.38 \%$ when in adsorption and $0.52 \%$ when in desorption mode.

The dynamic viscoelastic property is commonly evaluated by storage modulus $E^{\prime}$ and loss modulus $E^{\prime \prime}$. The $E^{\prime}$

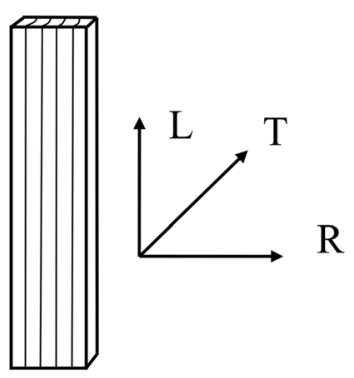

a

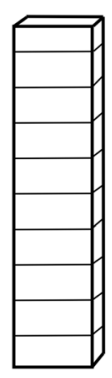

b

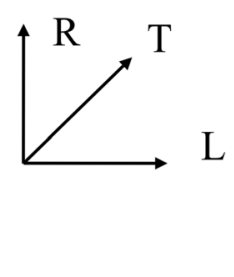

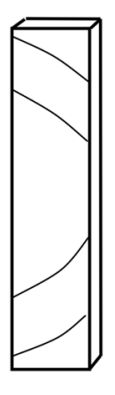

C

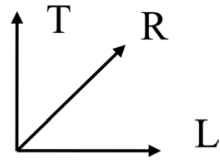

$\mathrm{L}$ 
describes the capacity of material to support a load and represents the elastic part of the material. The $E^{\prime \prime}$ is the viscous response of the material and proportional to its dissipated energy.

\section{Results and discussion}

\section{Moisture-dependent orthotropic storage modulus}

Figure 2 shows the normalized (n) data concerning $\mathrm{n} E^{\prime}$ for $\mathrm{L}$, $\mathrm{R}$ and $\mathrm{T}$ specimens with different $\mathrm{MC}$ at $1 \mathrm{~Hz}$. The normalized data are calculated as follows:

$\mathrm{n} E_{(T)}^{\prime}=E_{(T)}^{\prime} / E^{\prime}{ }_{-120}$

where the lower case " -120 " designates the corresponding data at the beginning of the temperature period (i.e., $-120^{\circ} \mathrm{C}$ ). The results clearly indicate a general falling trend of $\mathrm{n} E^{\prime}$ decreased with the elevation of temperature in all orthotropic directions, regardless of MC levels. With the elevation of measured temperature, wood cell wall polymers are provided with heating energy for segmental motions, resulting in a decrease in wood stiffness [5].

A general increase in $\mathrm{MC}$ lowered the values of $\mathrm{n} E^{\prime}$, regardless of temperature and grain orientation. Furthermore, different decreasing extents of $\mathrm{n} E^{\prime}$ with $\mathrm{MC}$ for $\mathrm{L}$, $\mathrm{R}$ and $\mathrm{T}$ specimens are observed. In order to clarify the decreasing extent of $n E^{\prime}$ during temperature elevating in all orthotropic directions at each MC level, the parameter of the decline of storage modulus $\left|\Delta \mathrm{n} E^{\prime}\right|$ was calculated as:

$\left|\Delta \mathrm{n} E^{\prime}\right|=\mid\left(\mathrm{n} E_{\text {(end) }}^{\prime}-\mathrm{n} E^{\prime}{ }_{-120} / \mathrm{n} E^{\prime}{ }_{-120} \mid \times 100\right.$

where the lower case "end" and "- 120 " designate the corresponding data at the end and beginning of temperature period, respectively.

Table 1 provides the variation of storage modulus $\left|\Delta \mathrm{n} E^{\prime}\right|$ for Chinese fir wood with six different MC levels in all orthotropic directions. An increasing trend with increasing MC is observed for the $\left|\Delta \mathrm{n} E^{\prime}\right|$ in all orthotropic directions. The graphical illustration of the $\left|\Delta \mathrm{n} E^{\prime}\right|$ reveals a nearly linear relationship with the MC (Fig. 3). The individual $\left|\Delta \mathrm{n} E^{\prime}\right|_{\mathrm{L}},\left|\Delta \mathrm{n} E^{\prime}\right|_{\mathrm{R}}$ and $\left|\Delta \mathrm{n} E^{\prime}\right|_{\mathrm{T}}$ are affected by the MC to a different degree. With a increase of $12.1-38.5 \%$ for $\left|\Delta \mathrm{n} E^{\prime}\right|_{\mathrm{L}}$, 30.5-57.5\% for $|\Delta \mathrm{n} E|_{\mathrm{R}}$ and 37.5-63.0\% for $|\Delta \mathrm{n} E|_{\mathrm{T}}$ over the measured $\mathrm{MC}$ range $(0.6-22.0 \%)$, the $\mathrm{n} E^{\prime}$ decline in $\mathrm{R}$ and $\mathrm{T}$ directions is more pronounced than that in $\mathrm{L}$ direction and the value of $\left|\Delta \mathrm{n} E^{\prime}\right|_{\mathrm{T}}$ is slightly higher than that of $\left|\Delta \mathrm{n} E^{\prime}\right|_{\mathrm{R}}$ at each MC level.

Only few references cover the anisotropic moduli for Chinese fir wood [3, 16-19]. Even less is known about the moisture dependency of the anisotropic moduli. The only work known so far to present the moisture-dependent Young's moduli for Chinese fir in all orthotropic
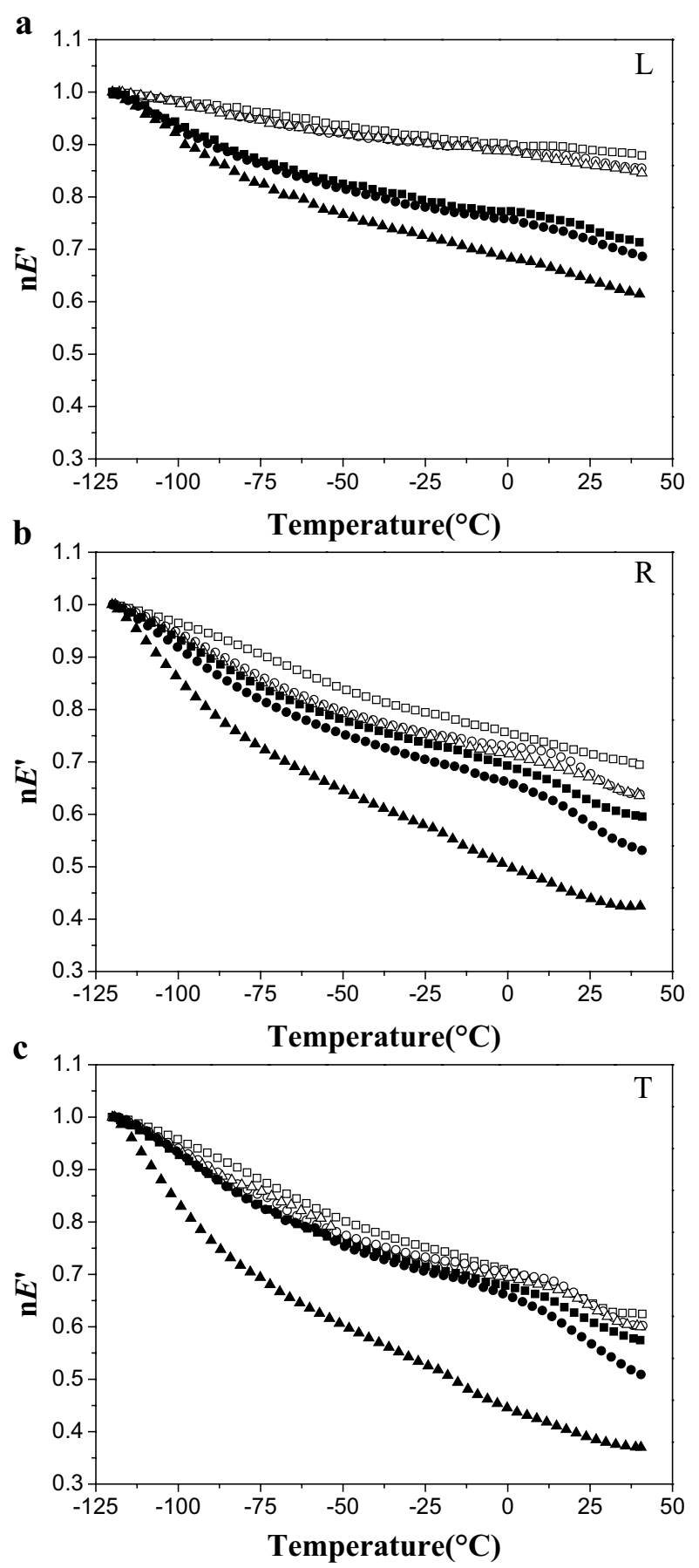

MC: $\square 0.6 \% \bigcirc 3.5 \% \triangle 6.0 \% \square 9.3 \% \bigcirc 14.1 \% \Delta 22.0 \%$

Fig. 2 Temperature dependences of normalized storage modulus $\mathrm{n} E^{\prime}$ for the L (a), R (b), and T (c) specimens with different moisture content (MC)

directions was recently published by Jiang et al. [3]. On the one hand, determined in tension, the Young's moduli and MC relationship published by the authors support the relationship obtained for the tensile storage modulus 
Table 1 The variation of $\left|\Delta \mathrm{n} E^{\prime}\right|$ for specimens with different moisture content (MC) in all orthotropic directions

\begin{tabular}{lllllll}
\hline Specimens & $\left|\Delta \mathrm{n} E^{\prime}\right|(\%)$ & & & \\
\cline { 2 - 6 } & $0.6 \% \mathrm{MC}$ & $3.5 \% \mathrm{MC}$ & $6.0 \% \mathrm{MC}$ & $9.3 \% \mathrm{MC}$ & $14.1 \% \mathrm{MC}$ & $22.0 \% \mathrm{MC}$ \\
\hline $\mathrm{L}$ & 12.1 & 14.5 & 15.4 & 28.6 & 31.3 & 38.5 \\
$\mathrm{R}$ & 30.5 & 36.2 & 36.4 & 40.4 & 46.9 & 57.5 \\
$\mathrm{~T}$ & 37.5 & 39.8 & 40.0 & 42.5 & 49.1 & 63.0 \\
\hline
\end{tabular}

$\left|\Delta \mathrm{n} E^{\prime}\right|$ the decline of storage modulus

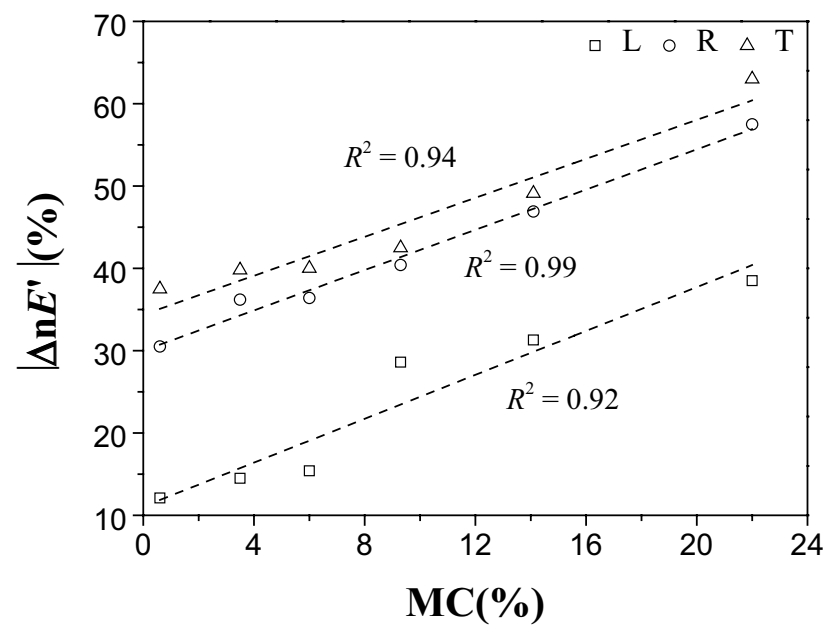

Fig. 3 Influence of moisture content (MC) on the decreasing extent of $\mathrm{n} E^{\prime}\left(\left|\Delta \mathrm{n} E^{\prime}\right|\right)$ in all orthotropic directions

presented in this study. On the other hand, while the authors showed that the Young's moduli $E_{\mathrm{L}}$ for wood are less sensitive to MC changes than the moduli in the directions perpendicular to the grain, the results presented here proved that storage $E_{\mathrm{R}}^{\prime}$ and $E_{\mathrm{T}}^{\prime}$ are affected by the MC to a higher degree than the $E_{\mathrm{L}}^{\prime}$.

The negative effect of adsorptive water could attribute to cell wall swelling, whereby fewer cell wall substances per unit area are available to resist the load [20,21]. More importantly, as water played the role of a plasticizer on chain segments of wood polymers, it formed water-paracrystalline cellulose, water-hemicellulose, and waterlignin bonds, which replaced hydrogen bonds within the polymer and caused the decrease of wood stiffness [4, 22-24]. In tension mode, the cellulose microfibrils and tracheids orientation in $\mathrm{L}$ direction are the reasons for its lower $\left|\Delta \mathrm{n} E^{\prime}\right|[17,25]$. Moreover, the influence of hemicellulose hygroscopic was more pronounced in the transverse directions [25]. Consequently, $\left|\Delta \mathrm{n} E^{\prime}\right|$ in $\mathrm{L}$ direction is less sensitive to MC changes than that in the directions perpendicular to the grain. The theories that ray cells acting as stiffening ribs and the serial earlywood and latewood cells in $\mathrm{R}$ direction may be plausible explanations for the lower $\left|\Delta \mathrm{n} E^{\prime}\right|$ in the $\mathrm{R}$ direction than that in the $\mathrm{T}$ direction $[3,16,17,26,27]$.

\section{Moisture-dependent orthotropic loss modulus}

Figure 4 shows the normalized (n) data concerning $\mathrm{n} E^{\prime \prime}$ for $\mathrm{L}, \mathrm{R}$ and $\mathrm{T}$ specimens with different $\mathrm{MC}$ at $1 \mathrm{~Hz}$. The normalized data are calculated by the following:

$\mathrm{n} E^{\prime \prime}{ }_{(T)}=E_{(T)}^{\prime \prime} / E^{\prime \prime}{ }_{-120}$

where the lower case "- 120 " designates the corresponding data at the beginning of the temperature period (i.e., $\left.-120{ }^{\circ} \mathrm{C}\right)$. From the $\mathrm{n} E^{\prime \prime}$ vs. $\mathrm{T}$ plot, three relaxation processes $\left(\alpha, \alpha^{\prime}\right.$ and $\left.\beta\right)$ were observed in $\mathrm{L}$ direction, while only two relaxation processes ( $\alpha$ and $\beta$ ) were exhibited in $\mathrm{R}$ and $\mathrm{T}$ directions.

Generally, the $\alpha$-relaxation process higher than $20^{\circ} \mathrm{C}$ was considered as the glass transition of hemicellulose $[16$, $26,28,29]$. The $\beta$-relaxation process at around $-90{ }^{\circ} \mathrm{C}$ was assigned to the reorientation of the methylol groups in amorphous wood cell walls and the reorientation of adsorbed water molecules in wood by many investigators [16, 30, 31]. The small $\alpha^{\prime}$-relaxation process around $0{ }^{\circ} \mathrm{C}$ only observed in $\mathrm{L}$ direction might be attributed to the melting of frozen water. This is in accordance with the findings published in Furuta et al. [11], where a similar trend that the $E^{\prime \prime}$ peak around $0{ }^{\circ} \mathrm{C}$ could be observed in the water or milled coniferous wood lignin (MWL) specimens. While the reasons for the absence of $\alpha^{\prime}$-relaxation process in $\mathrm{R}$ and $\mathrm{T}$ directions was still unclear, these difference between longitudinal and transverse directions indicated that the wood mechanical relaxation phenomenon affected by its orthotropic structure.

According to the results shown in Fig. 4 and Table 2 ( $1 \mathrm{~Hz}$ ), the $\alpha$-loss peak temperatures of L specimens were almost moved towards higher temperatures over $40{ }^{\circ} \mathrm{C}$ and were obviously higher than that of $\mathrm{R}$ and $\mathrm{T}$ specimens. The $\beta$-loss peak temperatures of $\mathrm{L}$ specimens with $\mathrm{MC}$ higher than $3.5 \%$ were lower than that of other two directions, which is opposite to synthetic composites that have higher loss peak temperatures in the stiffer direction. In general, the difference in transition temperatures among different structural directions was influenced by its specific structure [32]. It was also observed that the R specimens 

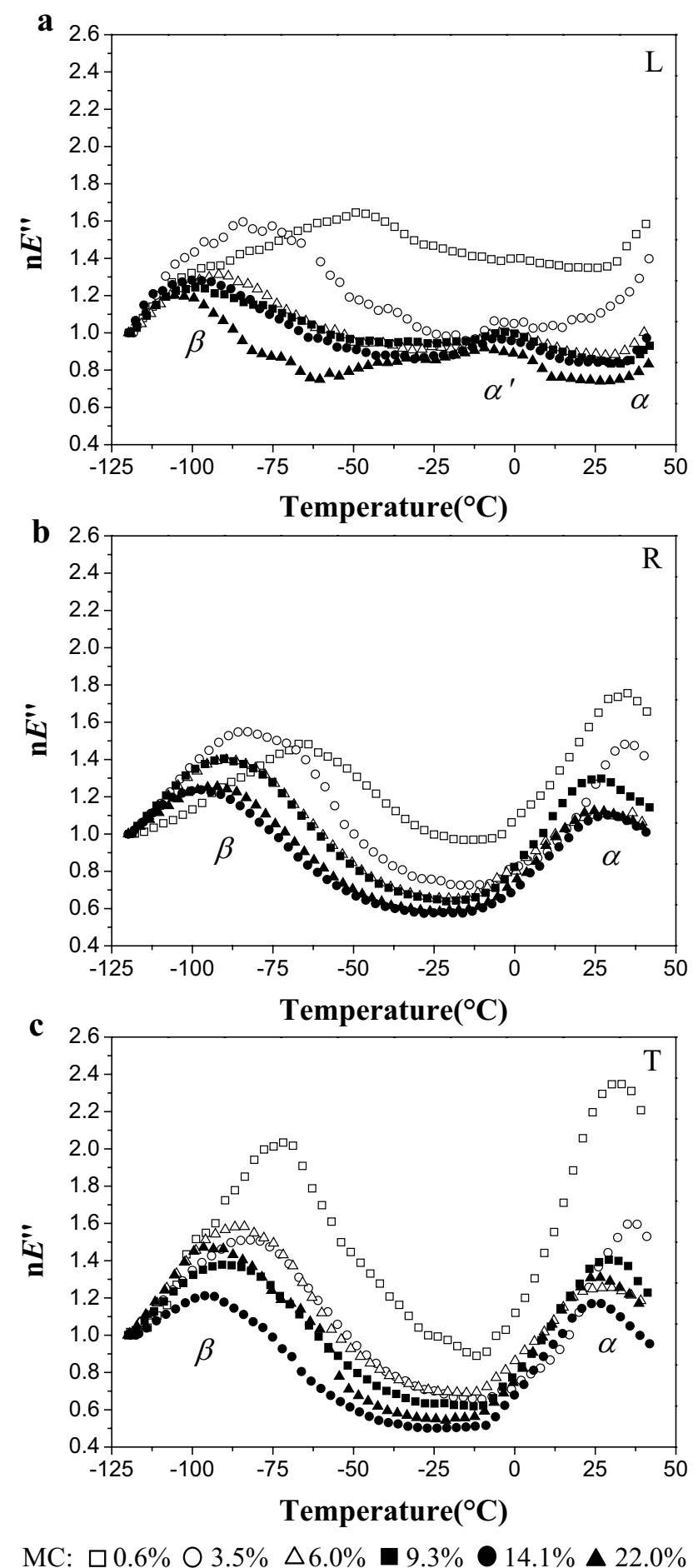

Fig. 4 Temperature dependences of normalized loss modulus $\mathrm{n} E^{\prime \prime}$ for the $\mathrm{L}(\mathbf{a}), \mathrm{R}(\mathbf{b})$, and $\mathrm{T}$ (c) specimens with different moisture content (MC)

generally had lower loss peak temperatures than that of the T direction for both $\alpha$ and $\beta$ transitions found in specimens with MC higher than $0.6 \%$. This discrepancy can be

reasoned that the latewood has more stresses in $\mathrm{T}$ direction than in $\mathrm{R}$ direction, while most strain occurs in the earlywood in R direction. Therefore, most $E^{\prime}$ and $E^{\prime \prime}$ signals came from latewood when they were measured in $\mathrm{T}$ direction and from earlywood when they were measured in $\mathrm{R}$ direction [26]. These results were in accordance with the findings of anisotropic loss peak temperatures published in Jiang and $\mathrm{Lu} \mathrm{[16].}$

The moisture-dependent $\alpha$ and $\beta$-loss peak temperatures for Chinese fir wood are presented in Table 2 $(1 \mathrm{~Hz})$. Generally, a decreasing trend with increasing MC is observed for both the $\alpha$ and $\beta$-loss peak temperatures in all orthotropic directions. Unlike the $\alpha$ and $\beta$-relaxation processes, the $\alpha^{\prime}$-loss peak temperatures in L direction was insensitive to changes in MC, while a increasing trend is observed for the intensity of $\alpha^{\prime}$-loss peak with increasing MC. This attributed to the fact that the more frozen water melted, the more dissipation energy occurred. When MC increased from 0.6 to $22.0 \%$, the $\beta$-loss peak temperatures moved from -49.3 to $-107.5^{\circ} \mathrm{C}$ for $\mathrm{L}$ specimens, -67.0 to $-98.3{ }^{\circ} \mathrm{C}$ for $\mathrm{R}$ specimens, and -70.2 to $-96.6{ }^{\circ} \mathrm{C}$ for T specimens. Similar to the $\beta$-relaxation process, the $\alpha$-loss peak temperatures moved from 34.3 to $24.7{ }^{\circ} \mathrm{C}$ for $\mathrm{R}$ specimens and 33.9 to $25.5^{\circ} \mathrm{C}$ for $\mathrm{T}$ specimens over the measured $\mathrm{MC}$ range. As water plays the role of a plasticizer, and it forms hydrogen bonds to lignin, hemicellulose, and para-crystalline cellulose. The plasticization effect of water lowered the energy required to initiate chain mobility, resulting in a decrease in $\alpha$ and $\beta$-loss peak temperatures. Moreover, according to Fig. 4, the intensity of both $\alpha$ and $\beta$-loss peak decreased sharply with increasing $\mathrm{MC}$ in all orthotropic directions, which indicated that less energy dissipation occurred due to the plasticization effect of adsorbed water molecules [11, 28].

To further compare per unit the amount of MC and the decrease of the loss peak temperature $\left(T_{\mathrm{LP}}\right)$ for Chinese fir wood in all orthotropic directions, a new parameter of $\mid \Delta T / \Delta \mathrm{MCl}$ was calculated as:

$|\Delta T / \Delta \mathrm{MC}|=\left|\left(T_{i}-T_{0}\right) /\left(\mathrm{MC}_{i}-\mathrm{MC}_{0}\right)\right|$

where the subscript " $i$ " designates the corresponding data when $\mathrm{MC}>0.6 \%$ and the subscript " 0 " designates the corresponding data when $\mathrm{MC}=0.6 \%$. According to Fig. 5, considering the relationship between the $T_{\mathrm{LP}}$ and $\mathrm{MC}$, the value of $\mid \Delta T_{\mathrm{LP}} / \Delta \mathrm{MCl}$ can be calculated from the slope of the regression line. The results reveal that the value of $\mid \Delta T_{\mathrm{LP}} / \Delta \mathrm{MCl}$ for $\alpha$-relaxation process in $\mathrm{R}$ and $\mathrm{T}$ directions is about 0.4 and 0.3 respectively, and that for $\beta$-relaxation process in $\mathrm{L}, \mathrm{R}$ and $\mathrm{T}$ directions is about $1.2,0.8$ and 0.7 , respectively. This indicated that compared with $\alpha$-loss peak temperature, the $\beta$-loss peak temperature was found to be sensitive to change in $\mathrm{MC}$ in transverse directions. Moreover, the individual $\alpha$ 
Table 2 The loss modulus $E^{\prime \prime}$ peak temperatures for specimens with different moisture content (MC) in all orthotropic directions

\begin{tabular}{|c|c|c|c|c|c|c|c|c|c|c|c|c|c|c|c|}
\hline \multirow[t]{2}{*}{ MC (\%) } & \multicolumn{5}{|l|}{$\alpha\left({ }^{\circ} \mathrm{C}\right)$} & \multicolumn{5}{|l|}{$\alpha^{\prime}\left({ }^{\circ} \mathrm{C}\right)$} & \multicolumn{5}{|l|}{$\beta\left({ }^{\circ} \mathrm{C}\right)$} \\
\hline & $0.5 \mathrm{~Hz}$ & $1 \mathrm{~Hz}$ & $2 \mathrm{~Hz}$ & $5 \mathrm{~Hz}$ & $10 \mathrm{~Hz}$ & $0.5 \mathrm{~Hz}$ & $1 \mathrm{~Hz}$ & $2 \mathrm{~Hz}$ & $5 \mathrm{~Hz}$ & $10 \mathrm{~Hz}$ & $0.5 \mathrm{~Hz}$ & $1 \mathrm{~Hz}$ & $2 \mathrm{~Hz}$ & $5 \mathrm{~Hz}$ & $10 \mathrm{~Hz}$ \\
\hline \multicolumn{16}{|l|}{0.6} \\
\hline $\mathrm{L}$ & 31.7 & $>40.0$ & $>40.0$ & $>40.0$ & $>40.0$ & 1.7 & 1.7 & - & - & - & -58.3 & -49.3 & -46.2 & -40.3 & -37.3 \\
\hline $\mathrm{R}$ & 30.5 & 34.3 & 36.0 & 37.5 & $>40.0$ & - & - & - & - & - & -70.0 & -67.0 & -64.0 & -54.9 & -52.0 \\
\hline $\mathrm{T}$ & 31.9 & 33.9 & 35.9 & 38.9 & $>40.0$ & - & - & - & - & - & -73.1 & -70.2 & -64.1 & -58.1 & --55.1 \\
\hline \multicolumn{16}{|l|}{3.5} \\
\hline $\mathrm{L}$ & $>40.0$ & $>40.0$ & $>40.0$ & $>40.0$ & $>40.0$ & 0.8 & 0.7 & 1.3 & 1.7 & - & -86.3 & -81.3 & -78.3 & -75.3 & -72.3 \\
\hline $\mathrm{R}$ & 29.6 & 33.1 & 35.6 & 37.1 & 38.6 & - & - & - & - & - & -87.8 & -82.8 & -79.7 & -76.8 & -73.8 \\
\hline $\mathrm{T}$ & 30.0 & 35.0 & 35.3 & 38.0 & 39.3 & - & - & - & - & - & -87.2 & -82.0 & -78.9 & -76.0 & -73.0 \\
\hline \multicolumn{16}{|l|}{6.0} \\
\hline $\mathrm{L}$ & $>40.0$ & $>40.0$ & $>40.0$ & $>40.0$ & $>40.0$ & 1.8 & 0.9 & 1.4 & 1.4 & 1.6 & -97.2 & -91.8 & -90.2 & -88.8 & -82.8 \\
\hline $\mathrm{R}$ & 27.5 & 30.5 & 33.5 & 36.5 & 39.0 & - & - & - & - & - & -91.5 & -89.5 & -86.5 & -80.5 & -77.5 \\
\hline $\mathrm{T}$ & 28.1 & 31.1 & 35.1 & 36.1 & 39.1 & - & - & - & - & - & -89.9 & -86.8 & -83.8 & -77.8 & -74.8 \\
\hline \multicolumn{16}{|l|}{9.3} \\
\hline $\mathrm{L}$ & $>40.0$ & $>40.0$ & $>40.0$ & $>40.0$ & $>40.0$ & -0.3 & 0.3 & 0.6 & 1.6 & 2.0 & -103.1 & -96.1 & -94.6 & -93.1 & -90.1 \\
\hline $\mathrm{R}$ & 27.0 & 29.8 & 32.8 & 35.8 & 38.8 & - & - & - & - & - & -96.2 & -91.2 & -87.2 & -84.2 & -81.2 \\
\hline $\mathrm{T}$ & 27.2 & 30.2 & 34.2 & 36.3 & 38.2 & - & - & - & - & - & -93.8 & -90.8 & -87.8 & -81.8 & -78.8 \\
\hline \multicolumn{16}{|l|}{14.1} \\
\hline $\mathrm{L}$ & $>40.0$ & $>40.0$ & $>40.0$ & $>40.0$ & $>40.0$ & 1.9 & 1.1 & 1.1 & 0.9 & 1.5 & -107.2 & -103.2 & -100.1 & -97.1 & -94.1 \\
\hline $\mathrm{R}$ & 25.8 & 28.8 & 31.8 & 34.8 & 37.7 & - & - & - & - & - & -98.2 & -97.3 & -94.2 & -91.2 & -83.1 \\
\hline $\mathrm{T}$ & 25.4 & 29.4 & 33.2 & 34.4 & 37.4 & - & - & - & - & - & -97.5 & -91.5 & -85.5 & -82.5 & -79.5 \\
\hline \multicolumn{16}{|l|}{22.0} \\
\hline $\mathrm{L}$ & $>40.0$ & $>40.0$ & $>40.0$ & $>40.0$ & $>40.0$ & -0.4 & 1.1 & 1.5 & -0.5 & 1.4 & -113.0 & -107.5 & -104.0 & -102.5 & -101.0 \\
\hline $\mathrm{R}$ & 21.7 & 24.7 & 30.7 & 33.7 & 36.6 & - & - & - & - & - & -99.3 & -98.3 & -94.3 & -86.3 & -85.3 \\
\hline $\mathrm{T}$ & 21.5 & 25.5 & 29.5 & 32.5 & 36.5 & - & - & - & - & - & -99.5 & -96.6 & -90.5 & -87.4 & -81.4 \\
\hline
\end{tabular}

$\alpha, \alpha^{\prime}, \beta$ three relaxation processes of loss modulus

and $\beta$-loss peak temperatures in $\mathrm{R}$ and $\mathrm{T}$ directions were influenced by the MC to a similar degree.

\section{Moisture-dependent orthotropic viscoelasticity measured at multi-frequency}

Figure 6 shows the dynamic viscoelastic properties $\left(E^{\prime}\right.$ and $E^{\prime \prime}$ ) of Chinese fir wood with different $\mathrm{MC}$ for $\mathrm{L}, \mathrm{R}$ and $\mathrm{T}$ specimens measured at $0.5,1,2,5$ and $10 \mathrm{~Hz}$. When the measurement frequency was increased, an increase in the $E^{\prime}$ and a decrease in the $E^{\prime \prime}$ were observed, regardless of the MC level and grain orientation. Meanwhile, the loss peak temperature location of $\alpha$ and $\beta$-relaxation processes shifted to the higher temperature range in all orthotropic directions (Table 2). These results were in agreement with previous studies [13, 33, 34]. In general, molecular motion was influenced by frequency and temperature. Increasing the measurement frequency, the segmental motion of wood main chain lagged behind the change of exterior force, and it would result in a relatively small interior friction $[33,34]$. Therefore, wood showed a rigid behavior, and higher temperature was needed to improve the chain segmental motion.
Furthermore, the $\alpha^{\prime}$-loss peak temperature of L specimens does not change with frequency, which could be proved that this small peak was attributed to the melting of frozen water.

According to Table 2, considering the relationship between the reciprocal of the absolute temperature $(1 / T)$ for the peak temperatures of $E^{\prime \prime}$ and the logarithmic frequency $(\ln f)$, the values of apparent activation energy $(\Delta E)$ of $\alpha$ and $\beta$-relaxation processes were calculated by an Arrhenius plot. By using the Arrhenius relation, the values of $\Delta E$ can be calculated from the slope of the regression line (Fig. 7). The $\Delta E$ of $\alpha$ and $\beta$-relaxation processes and the coefficient of determination $\left(R_{\alpha}^{2}\right.$ and $\left.R_{\beta}^{2}\right)$ are shown in Table 3. When MC ranged from 0.6 to $22.0 \%$, the $\Delta E$ of $\alpha$-relaxation process for $\mathrm{R}$ and $\mathrm{T}$ specimens was about $244.3-145.4 \mathrm{KJ} / \mathrm{mol}$ and $260.8-154.9 \mathrm{KJ} / \mathrm{mol}$, respectively. The $\Delta E$ of $\beta$-relaxation process for $\mathrm{L}, \mathrm{R}$ and $\mathrm{T}$ specimens over the measured MC range was about $68.3-54.1 \mathrm{KJ} / \mathrm{mol}, 67.1-48.4 \mathrm{KJ} / \mathrm{mol}$ and $66.7-45.6 \mathrm{KJ} / \mathrm{mol}$, respectively.

Obviously, the values of $\Delta E$ for $\alpha$-relaxation process were obviously higher than that of $\beta$-relaxation process. Moreover, different values of $\Delta E$ with $\mathrm{MC}$ for $\mathrm{L}, \mathrm{R}$ and $\mathrm{T}$ specimens were observed. For $\alpha$-relaxation process, the values of 

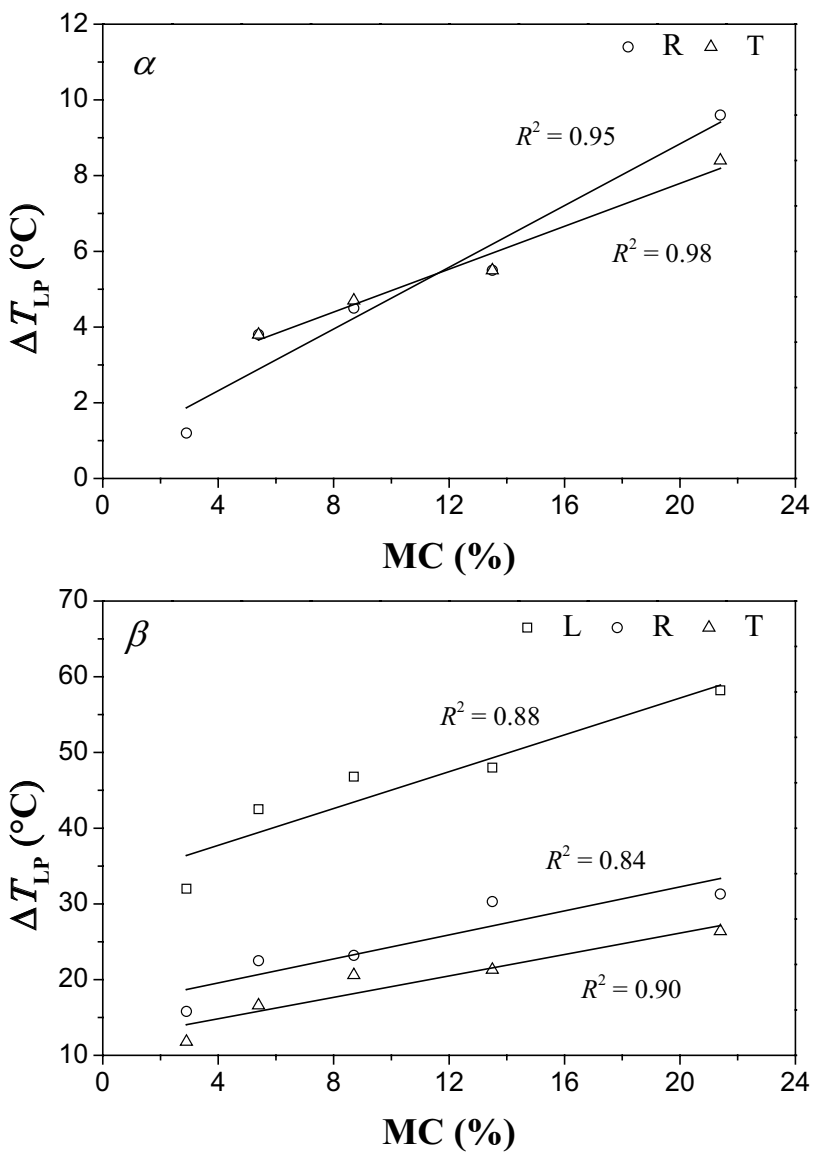

Fig. 5 Influence of moisture content (MC) on the $\alpha$ and $\beta$-loss peak temperatures $\left(T_{\mathrm{LP}}\right)$ in all orthotropic directions

$\Delta E$ had a general falling trend with increasing MC, regardless of grain orientation, which indicating more ductile with increasing MC. The decline of $\Delta E$ may result from the absorptive water, which act as a plasticizing agent for wood and lowered the glass transition temperature of hemicellulose. Consequently, it could be clear that the values of $\Delta E$ for $\alpha$-relaxation process were lower in higher MC level and wood chains or chain segments motion needed less energy. As for $\beta$-relaxation process, the values of $\Delta E$ showed a slight fluctuation with MC increasing, regardless of grain orientation. The changes of $\Delta E$ for $\beta$-relaxation process indicated that MC showed a complex effect on mechanical relaxation behaviour, and it was hard to establish a uniform trend of $\Delta E$ with MC. At $0.6 \% \mathrm{MC}$ level, the reorientation of the methylol groups in amorphous wood cell walls needed to cut off more hydrogen bonds, so it needed relatively higher energy. At 3.5\% MC level, the values of $\Delta E$ for $\beta$-relaxation process were higher than that for the $0.6 \% \mathrm{MC}$ samples in all orthotropic directions, which could be explained by the following points: on the one hand, with MC increasing, hydrogen bonds within the polymer network were replaced by the bonds to water molecule to make some of methylol groups released; on the other hand, mono-layer absorptive water molecules were formed in wood resulting in the larger size of the compound group of methylol groups and absorptive water molecules, which required more energy to reorientation. The increased of $\Delta E$ may be due to the effect of latter reason became more dominated. For the samples with higher $\mathrm{MC} \geq 6.0 \%$, the values of $\Delta E$ for $\beta$-relaxation process showed a general falling trend with increasing MC in all orthotropic directions, indicating that less energy was required. This result could be attributed to the reorientation of absorptive water molecules played the dominate role when multi-layer absorptive water were formed in wood cell wall. It was also observed that the $\mathrm{L}$ direction exhibited higher $\Delta E$ of $\beta$-relaxation process than that of the transverse directions, which may be associated with the stiffness cellulose orientation in $\mathrm{L}$ direction, thus hindering the reorientation of the methylol groups and adsorbed water molecules in amorphous wood cell walls, and these difference indicated that the wood mechanical relaxation phenomenon affected by its orthotropic structure.

\section{Conclusions}

The present study provides an overview on the moisturedependent orthotropic viscoelastic behaviors of Chinese fir wood with different MC determined in tension. The storage modulus $E^{\prime}$ and loss modulus $E^{\prime \prime}$ parameters were recorded in this research providing valuable data which can be used to a better understanding of the anisotropic and hygroscopic nature of wood under the low temperature environment. Based on this study the following conclusions can be made:

- With the double-effects of both temperature and MC, the storage modulus $E^{\prime}$ decreased in all orthotropic directions. The decline of storage modulus $\left(\left|\Delta \mathrm{n} E^{\prime}\right|\right)$ in the $\mathrm{R}$ and $\mathrm{T}$ directions is more pronounced than that in the $\mathrm{L}$ direction and the value of $\left|\Delta \mathrm{n} E^{\prime}\right|_{\mathrm{T}}$ is slightly higher than $\mid \Delta \mathrm{n} E \eta_{\mathrm{R}}$ at each MC level.

- With loss modulus $E^{\prime \prime}$, three relaxation processes $(\alpha$, $\alpha^{\prime}$ and $\beta$ ) were observed in L direction, while only two relaxation processes $(\alpha$ and $\beta$ ) were exhibited in $\mathrm{R}$ and $\mathrm{T}$ samples in the testing temperature range. The fact that a little $E^{\prime \prime}$ peak at around $0{ }^{\circ} \mathrm{C}\left(\alpha^{\prime}\right)$ was seen in L direction has scarcely been reported in the literature before. The $E^{\prime \prime}$ peak temperature location of $\alpha$ and $\beta$ processes shifted to the lower temperature range with increasing $\mathrm{MC}$ and the intensity of both $\alpha$ and $\beta$-relaxation peak decreased sharply with increasing $\mathrm{MC}$ in all orthotropic directions. Moreover, the $\beta$-loss peak temperatures were more sensitive to MC change than that of $\alpha$-loss peak temperatures in transverse directions. 

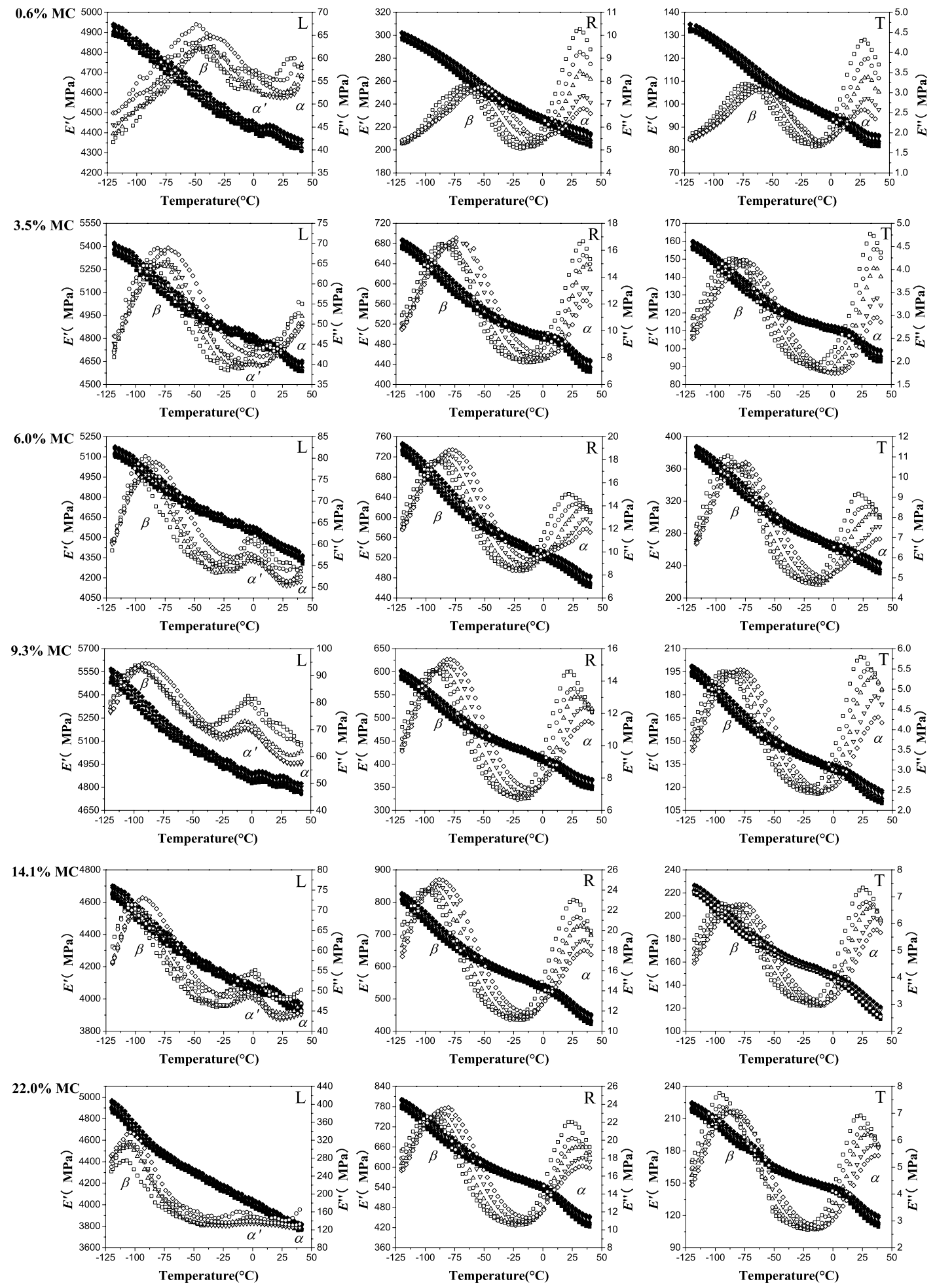

$$
\begin{array}{ccc}
\boldsymbol{E}^{\prime}: & 0.5 \mathrm{~Hz} \bullet 1 \mathrm{~Hz} \boldsymbol{\Delta} 2 \mathrm{~Hz} \nabla 5 \mathrm{~Hz} \diamond 10 \mathrm{~Hz} \\
\boldsymbol{E}^{\prime \prime}: & \square & 0.5 \mathrm{~Hz} \bigcirc 1 \mathrm{~Hz} \triangle 2 \mathrm{~Hz} \nabla 5 \mathrm{~Hz} \diamond 10 \mathrm{~Hz}
\end{array}
$$

Fig. 6 Temperature dependences of the storage modulus $E^{\prime}$ and loss modulus $E^{\prime \prime}$ for specimens with different moisture content (MC) measured at $0.5-10 \mathrm{~Hz}$ 

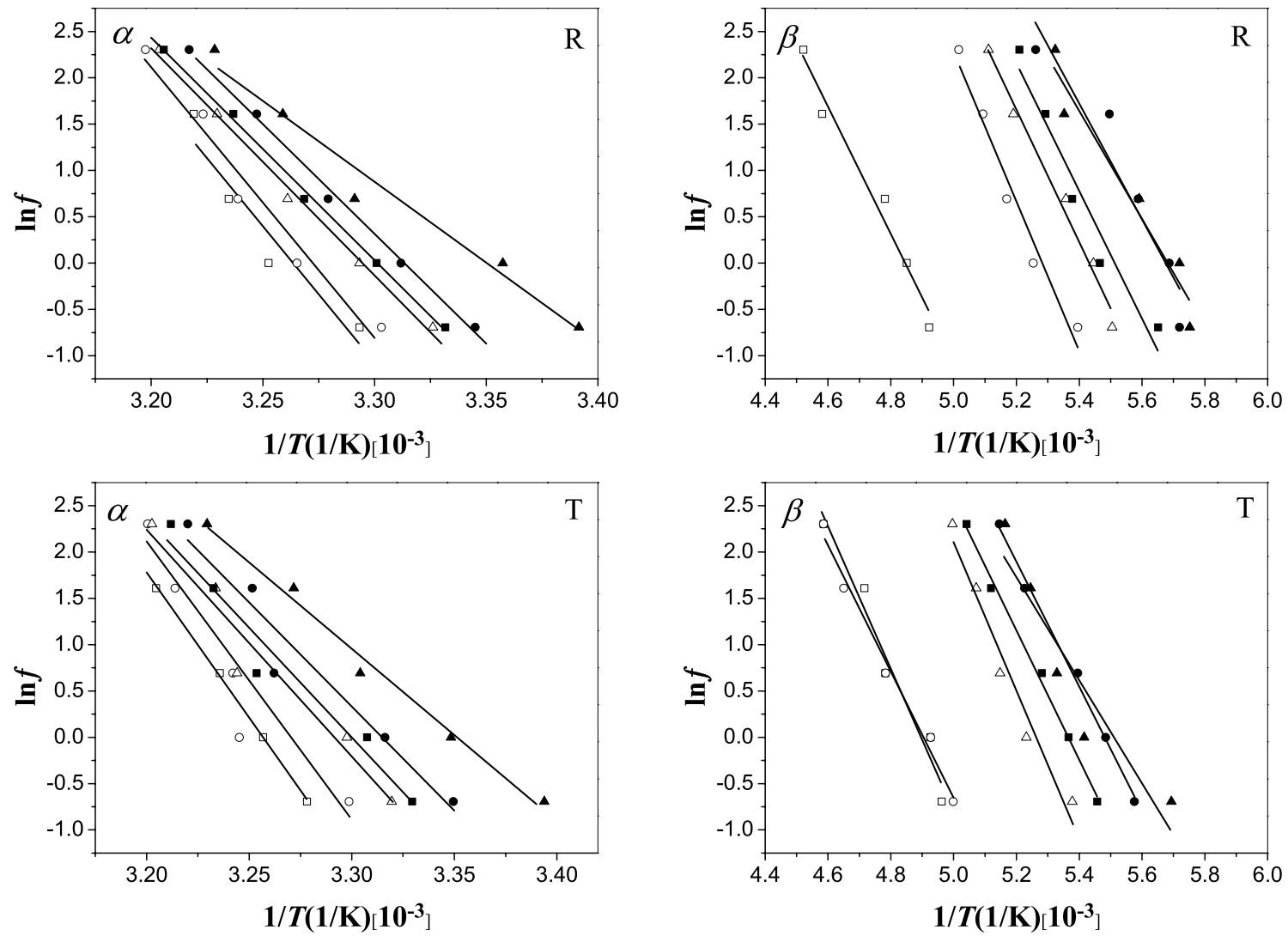

$$
\text { MC: } \square 0.6 \% \bigcirc 3.5 \% \triangle 6.0 \% \square 9.3 \% \bigcirc 14.1 \% \Delta 22.0 \%
$$

Fig. 7 Relationship between logarithm of frequency $(\ln f)$ at loss maximum and reciprocal of absolute temperature $(1 / T)$ for the L, R, and T specimens with different moisture content (MC)

- The dynamic viscoelastic behavior of wood is complex and also dependent on the measurement frequency. With the measurement frequency increased, an increase in the $E^{\prime}$ and a decrease in the $E^{\prime \prime}$ were observed. Meanwhile, $E^{\prime \prime}$ peak temperature location of the $\alpha$ and $\beta$-relaxation processes shifted to the higher temperature.

- The values of $\Delta E$ for $\alpha$-relaxation process decreased with increasing $\mathrm{MC}$ in all orthotropic directions, indicating less energy dissipation during the hemicellulose softening. However, the values of $\Delta E$ for $\beta$-relaxation process showed a slight fluctuation with MC increasing, regardless of grain orientation, which could be explained by the mechanism of interaction between wood cell wall polymer and moisture molecules. The differences of $\Delta E$ between $\alpha$ and $\beta$-relaxation processes could be attributed to its orthotropic structure and the value of MC. 
Table 3 The apparent activation energy $\left(\Delta E_{\alpha}\right.$ and $\left.\Delta E_{\beta}\right)$ at $0.5-10 \mathrm{~Hz}$ with coefficient of determination $\left(R_{\alpha}^{2}\right.$ and $\left.R^{2}{ }_{\beta}\right)$ for specimens with different moisture content (MC) in all orthotropic directions

\begin{tabular}{|c|c|c|c|c|}
\hline $\mathrm{MC}(\%)$ & $\Delta E_{\alpha}(\mathrm{kJ} / \mathrm{mol})$ & $R_{\alpha}^{2}$ & $\Delta E_{\beta}(\mathrm{kJ} / \mathrm{mol})$ & $R_{\beta}^{2}$ \\
\hline \multicolumn{5}{|l|}{0.6} \\
\hline $\mathrm{L}$ & - & - & 60.0 & 0.95 \\
\hline $\mathrm{R}$ & 244.3 & 0.91 & 57.2 & 0.98 \\
\hline $\mathrm{T}$ & 260.8 & 0.99 & 56.5 & 0.99 \\
\hline \multicolumn{5}{|l|}{3.5} \\
\hline $\mathrm{L}$ & - & - & 68.3 & 0.97 \\
\hline $\mathrm{R}$ & 242.7 & 0.96 & 67.1 & 0.97 \\
\hline $\mathrm{T}$ & 250.8 & 0.90 & 66.7 & 0.97 \\
\hline \multicolumn{5}{|l|}{6.0} \\
\hline $\mathrm{L}$ & - & - & 61.7 & 0.92 \\
\hline $\mathrm{R}$ & 204.1 & 0.99 & 59.5 & 0.99 \\
\hline $\mathrm{T}$ & 203.3 & 0.95 & 58.1 & 0.99 \\
\hline \multicolumn{5}{|l|}{9.3} \\
\hline $\mathrm{L}$ & - & - & 59.1 & 0.95 \\
\hline $\mathrm{R}$ & 199.9 & 0.99 & 57.3 & 0.95 \\
\hline $\mathrm{T}$ & 196.5 & 0.96 & 56.0 & 0.99 \\
\hline \multicolumn{5}{|l|}{14.1} \\
\hline $\mathrm{L}$ & - & - & 57.6 & 0.99 \\
\hline $\mathrm{R}$ & 197.0 & 0.99 & 52.0 & 0.91 \\
\hline $\mathrm{T}$ & 186.7 & 0.95 & 46.3 & 0.89 \\
\hline \multicolumn{5}{|l|}{22.0} \\
\hline $\mathrm{L}$ & - & - & 54.1 & 0.88 \\
\hline $\mathrm{R}$ & 145.4 & 0.97 & 48.4 & 0.95 \\
\hline $\mathrm{T}$ & 154.9 & 0.99 & 45.6 & 0.98 \\
\hline
\end{tabular}

$\Delta E_{\alpha}, \Delta E_{\beta}$ the apparent activation energy of $\alpha$ and $\beta$-relaxation processes, $R_{\alpha}^{2}, R_{\beta}^{2}$ the coefficient of determination for $\alpha$ and $\beta$-relaxation processes

Acknowledgements This research was sponsored by the Fundamental Research Funds of Chinese Academy of Forestry (CAFYBB2017QB005) and the National Natural Science Foundation of China (No. 31570548).

\section{References}

1. Hering S, Keunecke D, Niemz P (2012) Moisture-dependent orthotropic elasticity of beech wood. Wood Sci Technol 46:927-938

2. Ozyhar T (2013) Moisture and time-dependent orthotropic mechanical characterization of beech wood. Dissertation, ETH Zürich, Switzerland

3. Jiang JL, Bachtiar EV, Lu JX, Niemz P (2017) Moisture-dependent orthotropic elasticity and strength properties of Chinese fir wood. Eur J Wood Prod 75:927-938

4. Engelund ET, Salmén L (2012) Tensile creep and recovery of Norway spruce influenced by temperature and moisture. Holzforschung 66:959-965

5. Hernández RE, Passarini L, Koubaa A (2014) Effects of temperature and moisture content on selected wood mechanical properties involved in the chipping process. Wood Sci Technol 48:1281-1301

6. Miyoshi Y, Sakae A, Arimura N, Kojiro K, Furuta Y (2018) Temperature dependences of the dynamic viscoelastic properties of wood and acetylated wood swollen by water or organic liquids. J Wood Sci 64:157-163

7. Ayrilmis N, Buyuksari U, As N (2010) Bending strength and modulus of elasticity of wood-based panels at cold and moderate temperatures. Cold Reg Sci Technol 63:40-43

8. Drake G, Berry M, Schroeder D (2015) Effect of cold temperatures on the shear behavior of glued laminated beams. Cold Reg Sci Technol 112:45-50

9. Zhao LY, Jiang JH, Lu JX, Zhan TY (2015) Flexural property of wood in low temperature environment. Cold Reg Sci Technol 116:65-69

10. Zhao LY, Jiang JH, Lu JX (2016) Effect of thermal expansion at low temperature on mechanical properties of Birch wood. Cold Reg Sci Technol 126:61-65

11. Furuta Y, Obata Y, Kanayama K (2001) Thermal-softening properties of water-swollen wood: the relaxation process due to water soluble polysaccharides. J Mater Sci 36:887-890

12. Lenth CA, Kamke FA (2001) Moisture dependent softening behavior of wood. Wood Fiber Sci 33:492-507

13. Furuta Y, Okuyama T, Kojiro K, Miyoshi Y, Kiryu T (2014) Temperature dependence of the dynamic viscoelasticity of bases of Japanese cypress branches and the trunk close to the branches saturated with water. J Wood Sci 60:249-254

14. Hering S, Niemz P (2012) Moisture-dependent, viscoelastic creep of European beech wood in longitudinal direction. Eur J Wood Prod 70:667-670

15. Cao JZ, Zhao GJ (2001) Dielectric relaxation based on adsorbed water in wood cell wall under non-equilibrium state 2 . Holzforschung 55:87-92

16. Jiang JL, Lu JX (2009) Anisotropic characteristics of wood dynamic viscoelastic properties. For Prod J 59:59-64

17. Jiang JL, Bachtiar VE, Lu JX, Niemz P (2016) Time dependence of the orthotropic compression Young's moduli and Poisson's ratios of Chinese fir wood. Holzforschung 70:1093-1101

18. Peng H, Jiang JL, Lu JX, Cao JZ (2017) Application of timetemperature superposition principle to Chinese fir orthotropic creep. J Wood Sci 63:455-463

19. Peng H, Lu JX, Jiang JL, Cao JZ (2017) Longitudinal mechanosorptive creep behavior of Chinese fir in tension during moisture adsorption processes. Materials 10:931-945

20. Kaboorani A, Blanchet P, Laghdir A (2013) A rapid method to assess viscoelastic and mechanosorptive creep in wood. Wood Fiber Sci 45:370-382

21. Kulasinski K, Guyer R, Derome D, Carmeliet J (2015) Water adsorption in wood microfibril-hemicellulose system: role of the crystalline-amorphous interface. Biomacromol 16:2972-2978

22. Placet V, Cisse O, Boubakar ML (2012) Influence of environmental relative humidity on the tensile and rotational behaviour of hemp fibres. J Mater Sci 47:3435-3446

23. Zhan TY, Jiang JL, Peng H, Lu JX (2016) Evidence of mechano-sorptive effect during moisture adsorption process under hygrothermal conditions: characterized by static and dynamic loadings. Thermochim Acta 633:91-97

24. Zhan TY, Lu JX, Jiang JL, Peng H, Li AX, Chang JM (2016) Viscoelastic properties of the Chinese fir (Cunninghamia lanceolata) during moisture sorption processes determined by harmonic tests. Materials 9:1020-1037

25. Bergander A, Salmén L (2002) Cell wall properties and their effects on the mechanical properties of fibers. J Mater Sci 37:151-156

26. Backman AC, Lindberg KAH (2001) Differences in wood material responses for radial and tangential direction as 
measured by dynamic mechanical thermal analysis. J Mater Sci 36:3777-3783

27. Placet V, Passard J, Perré P (2007) Viscoelastic properties of green wood across the grain measured by harmonic tests in the range $0-95{ }^{\circ} \mathrm{C}$ : hardwood vs. softwood and normal wood vs. reaction wood. Holzforschung 61:548-557

28. Jiang JL, Lu JX (2006) Moisture dependence of the dynamic viscoelastic properties for wood. Beijing Forest Univ 28:118-123

29. Zhan TY, Jiang JL, Lu JX (2015) The viscoelastic properties of Chinese fir during water-loss process under hydrothermal conditions. Dry Technol 33:1739-1745

30. Kelly SS, Rial TG, Glasser WG (1987) Relaxation behavior of the amorphous components of wood. J Mater Sci 22:617-624
31. Sugiyama M, Norimoto M (1996) Temperature dependence of dynamic viscoelasticities of chemically treated wood. Mokuzai Gakkaishi 42:1049-1056

32. He MJ, Chen WX, Dong XX (2000) Macromolecular physics. Fu Dan Univ. Publishing House, Shang Hai, pp 224-228

33. Jiang JL, Lu JX, Yan HP (2008) Dynamic viscoelastic properties of wood treated by three drying methods measured at hightemperature range. Wood Fiber Sci 40:72-79

34. Zhan TY, Jiang JL, Peng H, Lu JX (2016) Dynamic viscoelastic properties of Chinese fir (Cunninghamia lanceolata) during moisture desorption processes. Holzforschung 70:547-555 